\title{
Article
}

\section{Aligning Action Research and Restorative Justice Highlighting Epistemological Tensions}

\author{
Brunilda Pali \\ KU Leuven
}

\begin{abstract}
The epistemology of participatory action research sets a high agenda for pursuing and engendering change oriented towards social justice. This article is based on a participatory action research project, anchored both in the principles of restorative justice and action research. The project aimed at mobilizing local participation, knowledge and resources and creating restorative dialogue and encounters in handling social conflicts in intercultural settings in four different countries. Restorative justice and action research are highly compatible in terms of some of their core principles, but the project revealed important tensions that this article will reflect upon. Zooming into a town in Hungary - one of the four action research sites - the article addresses these tensions by focusing on two central themes. The first theme, encountering the silence and micropolitics, relates to the challenges created in the site, due to our encounter with its micropolitics and the existing 'culture of silence' about social conflicts. How should researchers enter a site, how far should they stir the depths of conflicts and disturb the silence and status quo in order to unearth injustices, multiply narratives, and stage different perspectives? The second theme, rethinking conflict participation, relates to the tension created between a more naïve idea of participation and a more antagonistic one. In restorative justice, it is often assumed that if everybody were included and participated in restorative processes, staging their different perspectives, then consensus could be reached. But considering the possibility that different views cannot be reconciled, and power relations cannot be suspended, we need to rethink the meaning of conflict participation in restorative praxis.
\end{abstract}

Keywords participatory action research, conflict, social justice, restorative justice

In 2012, a collective of 30 researchers started a 4 years participatory action research (PAR) project. The project investigated the intersection of themes such as justice, security, conflict and interculturality. ${ }^{1}$ We researched these themes while setting up interventions in different local contexts in four European countries: Northern Ireland, Austria, Serbia, and Hungary. The main questions were: What are the perceptions,

\footnotetext{
1 ALTERNATIVE was an action research project conducted in the period 2012-2016 and funded through the Seventh Framework Programme (FP7) of the European Commission. The main objective of the ALTERNATIVE project was to provide an alternative and deepened understanding of justice and security based on empirical evidence of how to handle conflicts within intercultural contexts in democratic societies. The project was coordinated by the Leuven Institute of Criminology (LINC), in Belgium. The partners in the project were the Norwegian Social Research Institute (NOVA) in Norway, the European Forum for Restorative Justice (EFRJ) in Belgium, the Institute for the Sociology of Law and Criminology (IRKS) in Austria, the Foresee Research Group (Foresee) in Hungary, the Victimology Society of Serbia (VDS), and the University of Ulster (UU) in Northern Ireland.
} 
experiences, and practices of justice and security in our action research sites? How are they related to interculturality (if they are)? How can we influence and transform them through restorative praxis (actions and practices based on a restorative philosophy)?

But why did we start with these questions? We were reacting to discourses of (in)security which attributed inevitable social conflicts to intercultural contexts. As a result, culture has increasingly become a refracting lens through which conflict perceptions are formed in social conflicts, tensions and perceptions of insecurity (Stolcke 1995). Due to such discourses, exclusionary and immunitary mechanisms are created for social groups to coexist. Prioritizing security, these mechanisms endanger both justice and community (Esposito 2012, Brown 2005). We were set to counteract these tendencies by mobilizing local participation and create encounters and dialogue. We were convinced that such an approach had a better chance at creating a sense of security and a sense of justice that are rooted in the lifeworld of the individuals and of the groups participating in these processes. Crawford and Hutchinson (2016) have emphasized the importance of 'everyday security': the lived realities of security measures, including the diverse ways in which strategies and technologies of security governance are experienced, taken up, or resisted by different groups and individuals in society. Moreover, according to the authors, the more we study the 'everyday security', the better able we will be to expose the material inequalities, injustices, abuses of power, and differential social experiences that security projects create and maintain.

The inspiration for conceiving the application of restorative praxis in the context of security came partly from the Zwelethemba model in South Africa (see Shearing 2001, Roche 2002), the experiment known as the Community Peacemaking Programme. The idea of the Zwelethemba model was to develop a community-based conflict resolution process centered around the use of peace committees. Their overall objective was to mobilize and bring together local knowledge and resources to handle disputes and provide solutions to existing problems. While bringing about radical social changes was a task beyond the capacities of peace committees, the committees have attempted in various ways to address the underlying structural and social conditions which may have generated individual disputes (see Roche 2002, 525). In our project we hoped to do the same.

Given the scale and complexity of what we tried to do, the action research methodology appeared to be the best suited to both investigate some of the themes and their intersections, while engendering some form of social change through restorative praxis. Action research questions a priori a separation between knowledge and action, arguing that knowledge and change is possible and legitimate only through action (see McTaggart 2001, Tandon 1996, Cherry and Borshuk 1998). In more positivist and empirical forms of research, the knowledge that is generated is distanced from any immediate action and the pressures that this may exert on the research process. This is decidedly different in action research, where researchers become involved in various actions at the research sites and initiate interventions. Its purpose is not primarily or solely to understand social arrangements, but also to enact change as a path to generating knowledge. It has a transformative and emancipatory orientation towards knowledge, in that action can encompass any concerted effort to remove or influence any structural or ideological obstacles that hamper the growth of a group of people, 
community or organization (Kidd and Kral 2005, 189). It is this social justice orientation that pushes action researchers to move the process of change forward while increasing their understanding of the limitations that arise (Walsham 2006). Given this explicit orientation, action research cannot be value neutral. Action researchers aim to act morally and ethically to promote social transformation and social justice through research that is politically informed and personally engaged. The integration of theory, research, and action with an explicitly social justice agenda has been especially promoted and undertaken by the participatory strand of action research (see BrydonMiller 2001, Fine and Torre 2004, 2006, Lykes 2001, Reid and Vianna 2001).

Mostly used in educational, organizational, and health care settings, action research remains an underused but a highly interesting methodology for criminology and criminal justice research (see Aertsen 2018). Its alternative epistemology makes it particularly apt for scientific projects that aim both at investigating crime and justice related issues and at engendering change, especially at the level of criminal justice agencies or communities. In the criminological context, action research has been conducted in prisons (Hodiaumont et al, 2005, Crabtree et al. 2016, Sherwood and Kendall 2013), police (Walsh et al. 2014, Noga et al. 2016), crime policies (Wastell et el. 2004, Saija and Gravagno 2009), youth justice (Vanfraechem and Walgrave 2001), victim policies and restorative justice (Aertsen and Peters 1995). In particular, the restorative justice research group in the Leuven Institute of Criminology (KU Leuven) has a long tradition of action research which our project drew on (Aertsen 2018).

The particularity of our project design was its simultaneous reliance on both principles of restorative justice and action research. In this article, I want to illustrate some important challenges of doing action research by focusing especially on the ambivalences created at the intersection of action research and restorative justice in one of our action research sites. It is important for the reader not to equate this article with everything that has taken place in the Hungarian site, or in the whole project. The article is a very specifically framed and limited piece, centered mostly on selected methodological challenges. The project lasted four years and has produced many written and digital materials, which can be important sources for anyone interested in the intersection of themes such as justice, security, conflicts and interculturality, but also to those simply interested in applying action research to other subjects of study.

Through the project design which was anchored both in principles of restorative justice and action research, we set to mobilize local participation, knowledge, and resources to handle social conflicts. Restorative justice and action research were seen as highly compatible in some of their core principles. More specifically: the principle of lifeworldwhich means starting from a grounded and contextualized experience; the principle of participation - which refers to the engagement of the people concerned in the interventions that concern them; and the principle of transformation - which means creating and generating change of social structures, relations and practices. Despite this compatibility, it was in particular the intersection of a restorative justice 'philosophy' and the action research methodology with its own epistemological features, which produced the most interesting tensions and challenges in the project. These challenges are worth exploring in depth. 
This paper will zoom into one of the four action research sites, the town of Kisvaros 2 in Hungary, to illustrate some of these challenges that characterized the action research in the Hungarian site in particular and our project in general. Challenges and tensions, being important and accepted features of action research, were always articulated, discussed, and accounted for, rather than seen as obstacles or failures. The most useful insights which action researchers bring to scholarship, often have to do with how they have accounted for their positionality, how they have inquired into an issue, or how they have made sense of the interplay of contexts and interpretations. Following the introduction of the ALTERNATIVE project and the action research site, two central themes will be discussed. The first one, encountering the silence and the micropolitics, relates to the tensions encountered in the site with regards to its micropolitics and the existing 'culture of silence' about social conflicts. The second theme, rethinking conflict participation, relates to the tension created between a more naïve idea of participation and a more antagonistic one.

\section{Contextualising the ALTERNATIVE Project and Action Research in Kisvaros}

\section{The ALTERNATIVE project}

The project had at its core four case studies supported by and mutually feeding into three theoretically oriented work packages (WPs) and a comparative WP. The overall work was divided between 7 partners (research institutes). ${ }^{3}$ The four case studies were selected due their - initially perceived - different levels of 'intercultural conflicts' (micro, meso, macro). More specifically at the micro-level we selected the social housing estates in Vienna and focused on everyday conflicts between local residents (mainly between long term residents and residents with migrant background). At the meso-level, we selected an interethnic town (Kisvaros) in Hungary, focusing in general on the power relations and micropolitics, and on the position of the Roma minority in particular. At the meso/macro-level we selected three multiethnic towns in Serbia, focusing on interethnic conflicts between Serbs, Albanians, Muslims and Croats. At the meso/ macro-level, we selected three intercultural sites in Northern Ireland, focusing on conflicts between a local community and gangs of youths, between long term residents and recent immigrants, and on inter-community sectarian conflicts.

The selection of the sites was based on research and on consultation with local organizations who pointed either at the existence of 'intercultural conflicts' or at the 'culturalization of conflicts' (intercultural framing of conflicts) in their sites. Our project had to walk the fine line between both researching and intervening into 'intercultural conflicts' while at the same time challenging the intercultural framing of conflicts. Very early on in the project, we decided to use the notion of 'conflicts in intercultural settings' as an alternative to a frame of 'intercultural conflicts.' We hoped that through this less

\footnotetext{
2 Kisvaros is a fictitious name.

${ }^{3} \mathrm{KU}$ Leuven - where I was working - was the coordinator of the project. The Leuven team was mainly responsible for WP8 and WP1. WP2 and WP3 were covered respectively by the Norwegian Social Research Institute and the European Forum for Restorative Justice. The remaining four partners (Institute for the Sociology of Law and Criminology, the Foresee Research Group, the Victimology Society of Serbia, and the University of Ulster) were engaged in carrying out the local action research in their respective countries (Austria, Hungary, Serbia and Northern Ireland).
} 
'directive' and more 'open' framing we could question the necessarily assumed link between culture and conflict while still being able to investigate this link.

The theoretical WPs focused on the central concepts in the project. WP1 (Alternative epistemologies of justice and security) analyzed the concepts of justice and security. WP2 (Conflict transformation) analyzed the concepts of conflict and conflict transformation. WP3 (Restorative justice models) analyzed the concept of restorative justice and its models. A comparative work package (WP8) compared between the four case studies and attempted to align the local action research with the theoretical work. The project started in the first year with a discursive analysis of some of the main concepts that oriented the research: security and justice, restorative justice, conflict transformation, and active participation. By placing the concepts into a socio-historical framework, we aimed to understand under which conditions the concepts had emerged, how they have been used within a critical agenda but also how they have been recuperated by the neoliberal agenda. We hoped that this discursive approach would enable a more critical approach towards the fieldwork.

After constructing these discursive blocks of the theoretical framework, further steps were taken to prepare the ground for the action research in the 4 sites. During the first step, an in-depth mapping - through the methods of participant observation, document analysis, and interviews - was undertaken in each of the local contexts. The aim was to understand: a) the 'societal ecology' (like history and demography) of each site, b) the types of conflicts or conflict narratives existing, and c) the types of conflict handling mechanisms (if any) or patterns of conflict handling. This step went hand in hand with ongoing activities of trust-building on behalf of the local researchers in the sites, which eventually laid the ground for the sustained cooperation with the local inhabitants, the practitioners and other institutions' representatives.

After the in-depth mapping and preparing the ground, researchers have engaged in multiple tasks, like: a) sharing their research results with local participants, and b) making plans of actions for possible activities on the sites together with the local partners and participants. The actions have been tailored according to the context and consisted mainly in: a) offering workshops and trainings on restorative justice, b) intervening whenever possible in concrete conflicts taking place in the communities, and c) participatory filmmaking. Finally, the researchers have evaluated the actions both in terms of possible contribution of restorative justice to the societal challenges present in the sites, and in terms of challenges that the sites and the actions brought to the discourse of restorative justice.

By research design, my main task as a researcher based in the Institute of Criminology at KU Leuven, was generating propositional knowledge that could support the local research partners to interpret the findings and to design the actions in the research sites. My own role as part of the larger team was mainly focused on the reflection phases of the project. Participating in the action research as an outsider doctoral researcher meant that my concern with action research and the practices and actions thereby developed, was in relation to their contribution towards knowledge, more specifically to knowledge on restorative justice. For my $\mathrm{PhD}$ I have focused in-depth on only two of the action sites (Hungary and Austria), leaving out of the analysis Serbia and Northern Ireland. 
The reason for this was mainly due to the fact that the accounts from the Hungarian and Austrian sites were thickly ethnographical, accounts which enabled me to (partly) close the gap of not having been part of the local research team in these sites. Serbia and Northern Ireland have offered research material of a different register, having relied extensively on quantitative research methods. Furthermore, being 'post-conflict' societies with deep ethnic frontiers, they seem to invite for different interpretations and readings of certain concepts like interculturality, justice and security that went beyond the analysis I was able to conduct in my $\mathrm{PhD}$. Finally, it was a matter of deciding to conduct a rather more in-depth and saturated type of analysis of fewer case studies, as compared to a larger overview of all the four cases, which was the task of the comparative analysis in the project.

My main objective in respect to the two case-studies was instrumental (see Stake 2005), thus analyzing them in order to develop further insights about the discourse of restorative justice. But despite the instrumental objective, every case has been approached as intrinsically as possible, in line with the contextualist orientation of action research. Kingry-Westergaard \& Kelly (1986) have introduced the notion of contextualist epistemology, to highlight the fact that knowledge exists within a specific empirical and theoretical frame of reference. How action researchers decide which ways of knowing to use is fully dependent on the aim and the context of the project. Owing to that contextspecificity, there is neither a fixed formula for designing, practicing, and implementing action research projects, nor an overarching theoretical framework underpinning them. Because of its contextualized nature, knowledge generated from action research is cautious in its claims, sensitive to variations and open to reinterpretation in new contexts. In this paper, I focus in-depth on only one of the four action research sites: the Hungarian town of Kisvaros, hoping that if there are enough details provided, others may learn from it, and new theory can be generated to explain similar problems or issues in other contexts.

\section{Action Research in Kisvaros}

Since the change of the political regime in 1989, a great number of social programs and initiatives have been introduced in Hungary, seeking to mitigate the disadvantages of the Roma and foster their integration, mainly in the policy areas of housing, education, health care and employment. The change of the regime constitutes an important before-and-after narrative in the timescape for Hungary in general. On the one hand, the change of the regime has enabled the country and its citizens to enjoy liberties of a civil and political order, such as freedom of expression, freedom of assembly, freedom of religion, self-determination, and to develop grassroots movements. On the other hand, it has introduced many challenges of an economic order, such as poverty and unemployment, challenges which have influenced especially the Roma minority. Prejudice and discrimination towards the Roma, while always present, have increased, especially after the 2008 economic crisis and the rise in power of the right-wing government. Prejudice and discrimination, feeding on the social and economic insecurities of the Hungarian population, have enabled the framing of the Roma minority simultaneously as a crime (widespread use of the notion Gypsy criminality), as an economic and as a social problem. Such discourses have deepened the already existing rift and has contributed often towards the instigation of violent actions towards the Roma (see Berkovits and Balogh 2013). 
It is important to keep this context in mind when trying to imagine the town we selected for the action research: Kisvaros. Kisvaros is located about 40 kilometres from the capital of Hungary, Budapest and hosts about 2800 inhabitants. Despite its small size, there was at the time of the research a strong civil activity in town supported by the local government, more specifically 12 NGOs, 14 bottom-up initiatives and 4 local newspapers. The town had a kindergarten, a primary school, a high school, a library, a family doctor and a paediatrician. About $80 \%$ of its inhabitants considered themselves Catholics and the Catholic Church played a rather important role in the social and cultural life in the town. The town is intercultural, where German, Slovak and Roma minorities live beside the Hungarian majority. Despite their diverse cultural or ethnic origins, all the inhabitants of the town were Hungarian citizens. There were two local 'minority governments': the German and the Roma. The Roma minority was the largest in town, about 4\% self-declared and about $8 \%$ estimated. Compared to other interethnic towns in Hungary, Kisvaros had a reputation for being a peaceful town. There were at the time of the research no alternative or organized conflict handling services operating in Kisvaros, with the exception of a Civil Guard (a kind of volunteer 'neighbourhood watch' initiative). The absence of such formal or semi-formal mechanisms made the restorative work conducted by our researchers completely novel (see Hera et al. 2014).

The main reasons for selecting Kisvaros to conduct the action research were: a) the intercultural composition of the town, b) the relatively stable political dynamics and social environment that allowed for the development of a 4 years long research, c) the open attitude of its leaders and inhabitants to allow the researchers to engage with the town and conduct their research, and more pragmatically, d) the proximity of the town to the city of Budapest, where the research team was based. The action research in Kisvaros was conducted by the Foresee Research Group, a team of young researchers and mediators with many different skills and backgrounds, like sociology, conflict management, psychology, community building, law, criminology, and communication. This variety has enabled the team to allocate different people to different tasks within the project, such as research, application of restorative approaches, and filmmaking (see Szegő et al. 2018).

The main objective of the action research was to offer an answer to the question of whether applying a restorative approach to conflicts in an intercultural community was possible and how would this approach impact on the perceptions of justice and security. The research team created initially different types of partnerships ${ }^{4}$ with the community members in order to identify and map issues of local importance and relevance, local conflict dynamics, and local conflict handling mechanisms and patterns. After this initial stage, they developed methods and ways of studying, understanding and interpreting these dynamics, shared their insights with the community, and received feedback from them. Another stage was taking action on the resulting knowledge whenever appropriate and possible, and engendering interventions into existing conflicts (such as 'restorative

\footnotetext{
${ }^{4}$ In the form of Memorandums of Understanding, local support groups, discussion groups, research feedback groups, participation of researchers in local activities and participation of the locals in the project activities.may
} 
actions'). The last stage was engaging into the evaluation of the interventions and the research. The whole process entailed building and maintaining collective commitments and alliances between researchers and participants in the planning, investigation, implementation, and dissemination of the research process (see Benedek et al. 2015, Szegő et al. 2015).

\section{Reflections on Methodological and Conceptual Tensions and Challenges}

As mentioned above, the project design was anchored both in principles of restorative justice and action research, which were seen as highly compatible. For example, both action research and restorative justice are grounded on the principle of lifeworld, which more specifically means starting interventions based on the grounded and contextualized experience of the stakeholders. This is closely connected to the principle of participation which refers to the engagement of the people in interventions that concern them. Another principle that can be identified as connecting both approaches is the one of transformation, which means creating and generating changes within social structures, relations and practices. Despite this compatibility, there are other principles which set action research and restorative justice apart, for example the principle of restoration belongs exclusively to the restorative 'philosophy'. It was in particular the intersection of a restorative justice 'philosophy' and the action research methodology with its own epistemological features, which produced the most interesting tensions and challenges in the project, worth exploring in depth. Challenges and tensions, being important and accepted features of action research, were always articulated, discussed further, and accounted for, rather than seen as obstacles or failures. Herr and Anderson (2005, 69) have referred to this reflective and adaptive feature of action research as a process of 'designing the plane while flying it.' My intention is to reflect on some of the challenges, questions and dilemmas that we have encountered (see also Szegő 2018, Szegő et al. 2018, Hera 2018), focusing on two central themes: encountering the silence and the micropolitics and rethinking conflict-participation.

\section{Encountering the Silence and Micropolitics}

How do researchers enter a community to create respectful and collaborative relations? This is a question we had asked ourselves from the beginning in every research site, but which was especially pertinent in the Hungarian site. In the other sites, researchers often collaborated with existing and embedded local NGOs active in conflict resolution or community work in order to reach the community. In Kisvaros, the lack of such NGOs or services brought the researchers in constant and direct contact with the 'community', conceived here simply as local residents. Armed as we were with the intention to create respectful and collaborative relations, we were not fully prepared for 'encountering the micropolitics' of the research site (Herr and Anderson 2005).

The entry process in any community or social setting requires entry from a particular level, institution, or alliance. It is therefore impossible in any intervention to ignore the local social stratification, power relations and existing gatekeeper roles. The research team, in order to enter the action research site, had to create alliances with local actors, among whom important gatekeepers were the council, the mayor ${ }^{5}$ and the leader of the

\footnotetext{
5 In the last year of the research, the mayor and the composition of the council changed and this created new challenges in the research project.
} 
Roma Minority Government. On the one hand, these are local actors with whom it is necessary to forge alliances in order to be able to work in a certain space. On the other hand, they are also inevitably political actors, thus cooperation cannot be perceived as neutral or as 'independent' as we had aspired to. The research team was by default perceived as 'left-liberal' because of these initial alliances. At the same time, the topic of research ('interculturality'), aligned with a social justice agenda, seemed to fall under the agenda of the 'left' (very broadly conceived). What was additionally noticed by the researchers is that a general distrust towards 'strangers' can go hand in hand with distrust against political elites (see Szegő 2018, Szegő et al. 2018). But the most important insight we gained when considering entry in a research site through key decision makers and gatekeepers, is that the legitimacy given to the research team by the local decision makers cannot be assumed to represent automatically the legitimacy of all the people in the site. In other words, the locals had not asked for the research, and perceived it instead to some extent as top-down and imposed, despite all the intentions and efforts of the researchers to create a sense of community ownership.

Encountering the micropolitics in the action site went beyond the initial agreements with the political gatekeepers but was persistent throughout the research. Blase defines micropolitics as being 'about power and how people use it to influence others and to protect themselves. It is about conflict and how people compete with each other to get what they want. It is about co-operation and how people build support among themselves to achieve their ends' (Blasé 1991, 1). Micropolitical activity tends to involve relationships rather than structures, informal knowledge rather than formal information, identities rather than roles, and talk rather than paper (Morley 2016). It is therefore an extremely delicate equilibrium that researchers must navigate through, such as the hierarchy, resources, and behind the scenes interests of the community or institutions in which they work (Herr and Anderson 2005).

Micropolitical activity can both promote and impede change. The interdependence among norms, rules, skills, and resources creates a pattern of status quo that is often taken for granted, and therefore cannot be studied without explicitly being challenged. The idea of dynamic conservatism (Schon 1983) for example suggests that social systems and social institutions are self-reinforcing and closed to the idea of examination and change. They are considered dynamic in the sense that they spend a lot of energies in the maintenance of the status quo. This micropolitical activity and dynamic conservatism were part of the research site. The forces operating in Kisvaros can be identified as forces that attempt to keep the status quo - in terms of privileges, traditions, positions, religion, divisions - and forces of change, that challenge and dispute that status quo. In the words of a local inhabitants, such forces try to 'pull out the carpet from under their feet'.

During the initial phase, researchers focused on the types of conflicts, tensions and prejudices that affect community life in Kisvaros. Additionally, they researched the existing legal and institutional systems in the community, the main social actors and their communication patterns, and conflict and crime prevention mechanisms applied in town and their effectiveness. They also explored any additional social activity of the community in order to identify possible ways and channels to activate local residents. Initially indicated to be an island of peace, Kisvaros started to unfold in all its complexity and conflictual dynamics as a sleeping volcano. Already at the phase of the diagnosis, 
researchers came across a very fragmented environment of interests and alliances concentrated around patterns of conflicting lines that had to do with mobility, religion, ethnicity, socio-economic status, and political affiliation (see Hera 2015, 2018). A large number of people were involved in the research, and were given a chance at either creating a narrative or contesting one.

Furthermore, the mapping phase (also called 'problem diagnosis') in Kisvaros revealed a general attitude of silence and avoidance towards conflict-talk (talking about and around conflicts). Conflict and conflict-talk were usually feared by the inhabitants as a reason for breeding more conflict or throwing fire into the already existing ones. In case of existing conflict, the researchers found that judgment of right and wrong and allocating blame are the most common attitudes, whereas expressing different standpoints, clarifying matters and searching for solutions were neither default practices nor easy to instigate. The 'culture of silence' in relation to conflicts, led to stereotypical depictions and hardening of homogeneous entities within the town, and to resistance towards conflict transformation approaches. Silence, as poet Adrienne Rich writes in Cartographies of Silence, must not be mistaken for absence because silence can be a plan rigorously executed. By simply challenging the 'culture of silence' and instigating the culture of dialogue, researchers too were perceived as forces of change.

It was in a way the tension between the social justice orientation of action research that conflicted with the orientation of the restorative approach towards neutrality or impartiality. Inquiring into conflicts and power relations inevitably leads to finding patterns of exclusion, of doubtful decision-making, of wrongs and rights. In these cases, positions of objectivity, neutrality or impartiality become difficult to maintain. In the site, different interpretations of events existed. Different groups stated unambiguously that the truth was on their side. These truths were usually believed to be different and incompatible. They were also perceived to be hierarchical, where one truth tended to become the hegemonic one, depending on the different types of capital - symbolic, professional, cultural - that the more dominant group possesses. The complexity of the narratives or the background of the conflicts was most of the times perceived as bringing into the picture too much unnecessary information. The extra information complicates the categorical divisions within the community. In other words, inhabitants were not unaware of the 'other side of the story', as we assumed perhaps naively, but that these other sides of the stories were considered illegitimate, untrue or unnecessary to reach a final opinion or judgement.

As researchers with a restorative and a somewhat counter-security agenda, we questioned the way communication functioned in the town which we thought hardens positions and damages relations. We also underestimated the passionate investments for collective identities that people have and want to feed and keep, and the structural arrangements which they intend to maintain through the construction of these collective identities. Not all local inhabitants were interested in norm clarification, although they were familiar with practices that can lead to it, such as general assemblies, public hearings and so on. The reasons are to be found in convivial practices that try as much to unmake social boundaries, as to maintain and create them (Wimmer 2007). It is therefore not the case that the inhabitants do not know that the 'other also can be human,' but that in most of the cases they are not interested in pursuing the issue 
further. In order to construct their own homogeneous identity and to keep their power over certain structures and resources, they inevitably need to exclude.

Despite the acknowledged principle of multi-partiality on behalf of the mediators, locals did not seem to believe in it. While the researchers were committed to 'hearing things from all sides' (central feature of restorative approaches), the local inhabitants were convinced that taking sides is a natural and unavoidable phenomenon. The cases the researchers identified and dealt with had often to do with exclusion, refusal, stereotypes, injustice towards mainly the Roma population, and therefore an invitation to tackle the conflict cannot be perceived as neutral. The mere action of asking certain people - for example the Roma - to tell their stories and to speak their own truths became a potentially subversive act. This indicated that in certain cases, open verbalization of hidden conflicts or giving voice to repressed or silenced narratives of conflicts may be even more important than the outcome of achieving consensus between different parties.

This became very obvious for example during the making of the final film 6 by the researchers, which turned out to be a source of conflict and has not yet acquired permission to be released. More particularly, the film depictions and representations of Kisvaros done by the researchers were not appreciated by everyone for having given voice and face to inhabitants who were not considered by others as important representatives of the community. In other words, the majority (literally speaking) of the locals are comfortable with the way things go, and do not appreciate new initiatives that try to democratize or open up participation into activities and public life. Who has the right to speak on behalf of a community therefore does not seem to be a naïve issue that can be left to researchers, but is clearly a heavily contested issue. The conservative middle class were disturbed by the opinions of the oppressed and marginalized. They wanted to maintain a good reputation and good image of their village and themselves. The (new) mayor and the council members wanted an image of them as being tolerant and inclusive, when they were not. The first two films had been accepted because they were produced during the time of the previous mayor, who had given the researchers access to the site.

The quote below belongs to an interview of the researchers with a local inhabitant after having shown their film to ask permission but also to use the material further as a research tool.

Events belongs to the community. This is how a community is built up and becomes a community. Those who accept the values of the community and want to be members of the community...it's a value. [...] Obviously, the ones who arrived from somewhere else...it is difficult for them to accept these values. However, they should not make jokes about these values. [...] There are inhabitants who moved to Kisvaros and are talking in this film in a degrading way about what is going on here, saying 'everything is terrible and nothing works. Local residents are stupid. They are doing silly things' [...] The native

\footnotetext{
6 Three films in total have been produced by the Foresee Research group. The first two can be found at http://alternativefilms.euforumrj.org/foresee-research-group-2/
} 
villagers $[\ldots]$ were strongly harmed. And it is terribly difficult to heal such a harm (local inhabitant, Kisvaros).

The inhabitant (a so-called 'native villager') is complaining about the fact that the film shows interviews with 'newcomers' - a category that can hardly be taken literally since one can still be a newcomer for 20 years - and that these interviews, both in content and representation harm the community. Several local residents even assumed incorrectly that it was the (old) mayor who selected the residents with whom the researcher got in contact. Some other local residents felt offended because they were not chosen to be interviewed. Researchers were told that the people that had not been interviewed were 'powerful', 'serious' people who 'have an impact on the whole village'. It was assumed immediately that 'they were not asked', thereby presupposing an intention behind this neglect. In reality, some of these people refused to share their opinions and be represented in the films. What the researchers did not capture became as important as what they captured. The filming and its different versions could be used eventually both as a research and as a communication tool, but it was hard to come up with one final common film which could be accepted, thus it could not become a tool for consensus.

Hearing another voice which is different, can only be accepted or tolerated therefore on two conditions: when the voice has no real weight and when it does not attempt to be part of the community. Participation is appreciated by the majority when it allows the inclusion of that voice which is already hegemonic, or when it is not disruptive of the status quo and of the existing power relations. Any social actor that will attempt the opposite will automatically be perceived as an agitator of sorts. The intention of the researchers to create a democratic representation of voices by bringing in subjugated voices that are left outside the normal consensus and power arrangements therefore turned out to be a radically subversive act. The role of the researcher as an 'uninvited outsider' who has the potential to disrupt local dynamics and to rearrange social forces, led to acceptance by those who welcome this, and rejection by others who felt threatened by it.

The conflict about the film ${ }^{7}$ and the film becoming a source of conflict in itself showed the need to appreciate every instance where restorative actions make visible and sayable that which a particular configuration of power renders less available and less legitimate. An achieved unification of the diversity of voices might signal that power has been imposed somewhere, that some voices have been silenced, and that dialogue has been blocked by a monologizing and hegemonic force (Bakhtin 1981). The researchers as action researchers have to accept the difficulty and perhaps the impossibility of adopting a non-biased position and of being equally credible to different groups, which the restorative 'philosophy' calls for.

\footnotetext{
7 For a detailed account of the 'story' of the film in the Hungarian site, a comparison to the other filming experiences in the project, and especially some of the ethical dilemmas the filming experiences raised, see: Szegö, Dora 2018. "Participatory filming as part of action research in ALTERNATIVE: Experiences from four countries." In Action Research in Criminal Justice: Restorative justice approaches in intercultural settings, edited by Inge Vanfraechem and Ivo Aertsen, 43-59. London and New York: Routledge.
} 
First of all, our starting point was that conflicts are the ownership of the people. The roots of the idea of participation as ownership lie in Christie's (1977) argument in Conflicts as Property, a foundational text of restorative justice. Starting with the assertion that modern society is characterized by too little conflict because conflicts have been stolen by professional and structural thieves, Christie argued that they could be stolen because they are a form of property. For the direct parties to be empowered and enabled to deal with their own conflicts, the state and its experts must be disempowered. At most they must act as resource-persons who support the staging of conflicts, instead of stealing them (Christie 1977, 12). Ownership8 therefore is for Christie the reason for and the route towards participation. Turning to action research, according to Reason and Bradbury, participation is the defining characteristic of action research, providing opportunities for co-developing processes with people rather than for people (Reason and Bradbury 2001, 9). Highlighting the distinction between 'involvement' and 'participation' in participatory action research, McTaggart argues that 'authentic' participation means that the participants fully share 'in the way research is conceptualized, practiced, and brought to bear on the lifeworld' (McTaggart 1997, 28).

Secondly, we also believed that participation could contribute to counter racism, exclusion, prejudice and injustices, and elicit a certain political consciousness of belonging and of acting in cooperation with others. The restorative approach insists on setting up dialogic meetings and personalized encounters between people who either do not usually meet, or who hold stereotypical, categorical images and misconceptions about each other. This relies on the idea that such meetings will lead people to acquire a sense of complexity which leads to change the representation of the 'other', by promoting more accurate perceptions, disabling stereotypes and misattributions, and eventually build trust and instigate common and collective actions. The assumption is that the restorative process can provide safe environments for people in conflicts to share their personal stories, pains and strengths with an equal chance for every participant to talk, to listen and be listened to. If the participants move from their initial positions and better understand the underlying causes of the other side's decisions, dilemmas and perspectives, the result is expected to be a more trusting, accepting and less labelling community, a community that can move more easily towards collective collaboration and actions.

Let me consider these assumptions one by one in order to highlight the dilemmas. First, the idea of conflict-ownership. We tried to adhere to the principle of full participation and to the 'conflicts as property' to the largest extent possible, but the gap was unavoidable. Cornwall (1996) has proposed a typology of participation/collaboration in an adapted continuum that goes from co-option, compliance, consultation, cooperation, colearning, all the way to collective action. Without going into extensive details of this typology, it is clear that the type of participation/collaboration that we could realize in the project falls midway at the level of cooperation. At this level, local participants work together with 'outsiders' (researchers) to determine priorities, but the responsibility remains with 'outsiders' to determine the process. The highest level of participation

\footnotetext{
8 Despite the fact that Christie has been sometimes read as promoting conflict as a private property, reading him carefully shows that Christie's notion of 'conflicts as property' means neighborhood (thus common, public, community, or civil society) property rather than private property.
} 
(collective action) in any form of action research is when the local actors set their own agenda. Given that the research agenda was set from the start from both funding and research institutions that started the research, the project was far from having reached the optimum level of participation. Once the research agenda had been set, all the necessary steps have been taken to ensure constant participation at all levels, but that initial agenda setting on behalf of the researchers made a huge difference.

Some inhabitants expressed lack of trust towards the researchers not being sure why they were there and who sent them. It is a recognized feature of any research project that researchers can be greeted with various responses, including unfavorable ones, but action research projects in general, and participatory action research projects in particular, depend heavily upon the establishment of an environment of trust. Some wondered why their town was chosen, some even thought that problems were so serious that they needed help from the outside, and some questioned the utility of researching conflicts:

We have lived here in peace. If they snoop around looking for conflicts, they will find some for sure, or stir them up by asking about them. That's exactly what we don't need. Conflicts have always been around, and we can very well live with them, we do not need to blow them up (local inhabitant, Kisvaros).

This quote is a very important one and reflects one of the main dilemmas of action research: its precarity, when not designed from the beginning with the community on $a$ problem that the community thinks is a problem. This has been a serious dilemma throughout the research in the site of Kisvaros. Our research offered no answer to that dilemma. Most of the conflicts we encountered had to do at their roots with exclusion and injustice. In cases of such conflicts, researchers found it difficult to involve all the parties as required by the restorative approach. The parties invited to the dialogue rejected the invitation in many cases, as that would have implied: first, admitting having done wrong and accepting having harmed the other party; secondly, having to take responsibility for the consequences of ones' actions, and; thirdly, accepting to engage in some form of power sharing. Conflicts became more prominent and more salient when they had to do with the use of semi-public and public spaces, including civil society initiatives and media control which had to do with presence, representation and voice.

Our fundamental question was who would think that the exclusion of the Roma from playing football, from participating in a local festival, from receiving material distribution, or becoming a civil guard is a problem? These are considered to be problems mainly by the Roma themselves, and perhaps by those committed politically or civically to social inclusion in general. How possible and realistic would it have been to decide together with this 'community' as a whole that this exclusion of the Roma from civic life and the harm it causes are important problems worth either researching or acting upon? Is there anything like a 'whole community'? I turn to this last question in what follows, by tackling the second assumption of our research. 
What about our assumption that participation in restorative approaches will reduce social exclusion and other social harms? We believed that given the need in such communities for clarification of norms and values, and given the insecurities and distrust about the others, any encounter can be argued to be productive in so far as it reduces the social distance and drives people towards collective actions. The idea that face-toface encounters and contact will change the representation of the other in a positive way is a deep assumption of restorative justice that often goes unchallenged. Linked to this, another assumption is that if everybody were included and would participate, then some form of agreement and consensus could be reached. Reminiscent of Habermas' ideal speech situation, this belief relies on an idea of participation that offers a space in which all voices are equally listened to. In this situation, power relations would be completely suspended, thus giving every participant the freedom to speak freely and have their views listened to and taken seriously. Eventually, all the participants would come to a consensus about the best course of action, having taken everyone's views into account and rationally debated the pros and cons of every possible course of action.

Chantal Mouffe (see Miessen 2010) calls this a pluralism without antagonism, which acknowledges that there are different points of view, different interests, different values, and creates the need for putting ourselves in the shoes of other people, imagining that when all these values are put together, they would constitute a harmonious ensemble, each playing its part. Rather on the opposite, Mouffe argues for the ever-present possibility of ineradicable antagonism, which means that a consensus without exclusion is always unavailable. The dissociative view of the political, which she identifies with, holds the idea that pluralism necessarily implies antagonism, because all the different and multiple views cannot be reconciled, and some of them require the negation of other views. Moving beyond the idea of 'antagonism proper', which is the friend-andenemy relation, she calls these relations agonistic, conceived as relations of adversaries, or 'friendly enemies'. Mouffe argues that agonism as a constructive form of political conflict might offer an opportunity for a constructive expression of disagreements and dissensus. This would happen by creating institutions that will allow for conflict to emerge and be expressed. If that agonistic form of conflict handling is not available, according to Mouffe, it is very likely that, when conflicts emerge, they are going to take an antagonistic form.

In the research site, most residents were resistant to norm-clarification and dialogue, as they did not want to unmake their social boundaries and question their power relations. The differences in power relations lead to different interpretations of conflicts. While the Roma interviewees reported discrimination or discriminatory practices, prejudice, disadvantages at workplace and even life-threatening conflicts, the non-Roma used the usual familiar stereotypes about the Roma: their criminality, their unwillingness to change their lives, their laziness and lack of hygiene. Structural explanations were rare, and exclusion of the Roma was explained within an individualizing and essentializing perspective. Such perspectives emphasized either the responsibility of the individual or the naturalness of the ethnicity, illustrated by phrases such as 'it's in their blood'. The stereotypes and perceived differences were not simply 'folkloric', but often became the main justification for exclusion from the civil and political life of the town (from football clubs, from festivals, from civil guard initiatives, and from distributive policies). Membership and belonging to the community are constantly contested. 
'Newcomers' (this does not have to do with time, as one can be a newcomer for 20 years) are not accepted as belonging unless they unconditionally accept and follow the local ways. Belonging to a minority is well accepted by the majority when the minority members 'know their place'. 'Knowing one's place' goes beyond demands for unconditional acceptance into (majority) community life, towards worrying immunitary tendencies, which become evident by the usage of words such as blood and genes to articulate differences. Often the boundaries are maintained as much by what is said as by what is unsaid. They are not explicitly articulated, but assumed, or hinted at.

We tried to understand those boundary-making processes through our research orientation, while at the same time they challenged our restorative orientation which aims largely at unmaking boundaries. In our dilemma, Roberto Esposito's rethinking of community versus immunity, and immunity versus auto-immunity became important. Esposito argues that while a certain level of immunity is not only healthy but vital to a community, it is when the level of immunity becomes so high that it turns into autoimmunity that a community is endangered. Thus, it is not boundary-making (or maintenance) in itself that is a problem, but rigid and hermetic boundaries which can fuel homogenization, essentialization, or even demonization of the other. Boundarymaking therefore has to go along with simultaneous processes of boundary-unmaking of self and other that keep a certain level of flow back and forth between different members in the communities. The main problem of 'difference' is never difference per se but the fact that differentiation processes reveal themselves as hierarchies and dichotomies (if you are good then the other is evil). The implication of this analysis is that processes of framing, identification, and boundary-(un)making are fundamentally political.

With all these dilemmas in front of us, it became important in our research to move away from a romanticized or placatory notion of participation into a more proactive, conflictual model of engagement. Participation can be a cunning rhetoric and strategy that leads to a pre-established consensus and reinforces the existing power relations, or it can be disruptive, create dissensus and challenge the existing power relations. Christie's original notion of conflict-participation which aims at eliciting norm-clarification practices, staging of dissensus, and conflict nurturing, seem to us to be better objectives for restorative praxis with an orientation towards social justice. Pavlich envisions restorative interventions as forums designed to bring conflicts to the 'forefront of political theatre' (Pavlich 1996, 152). Sharing Christie's aim of norm clarification, for Pavlich too, conflict can be one of the most important ways and means for locating and communicating contradictions, inequities and injustices that affect some people in their social formations. This designation of conflict-forums as a 'political theatre' is extremely useful, but also highlights the difficulty of starting processes of norm-clarification. Often, engagement is avoided because people know that it is not in their (political) interest, and they will show resistance to such ideas and practices rather than embracing them. At the same time, it also highlights the need to move in such contexts beyond the element of reparation towards more transformative objectives and strategies, in line with action research epistemologies. 


\section{Conclusions}

Action research remains an underused but an infinitely interesting methodology for social scientists in general and criminologists in particular. Its alternative epistemology makes it particularly apt for scientific projects that aim both at investigating social issues and at engendering social change. Action research is neither a shiny nor a neat science. The honesty and a detailed narrative of researchers about their work (especially the challenges encountered) are the most valuable results that action research can pass on to other researchers.

The first challenge I highlighted here has to do with the micropolitics of action research sites. It is crucial for action researchers to keep in mind that the entry process in any research site requires entry from a particular level, institution, or alliance. It is therefore impossible in any intervention to ignore the local social stratification, power relations and existing gatekeeper roles. The cooperation that will be enabled will depend on the gatekeepers. The notion of a 'gatekeeper' might be tricky in this regard, because it given the illusion that the 'gatekeeper' in indeed he or she that holds control to the otherwise closed gates. In this article, I tried to problematize this image, arguing instead that due to alliance with one 'gatekeeper' some gates might open, but others will be especially closed. This might be often still the only way researchers have to enter a research site, but it is important to consider its impact. Micropolitics is different from the 'obvious politics', therefore it might require special skills from the researchers, who have to navigate such complicated contexts unfolding through relationships, informal knowledge, identities, and talk (Morley 2016). Another important point for action researchers to consider is that due to the micropolitics, it is very common for their interventions to be supported by some members of the community and not others. This was challenging especially for us as 'restorative researchers' whose intention was to take everyone on board on our project.

Another very real challenge we encountered in this regard, was what we identified as a 'culture of silence', a general attitude of silence and avoidance towards conflict-talk. The 'culture of silence' in relation to conflicts, led to stereotypical depictions and hardening of homogeneous entities within the town, and to resistance towards conflict transformation approaches. What we thought to be initially only somewhat a 'problematic pattern of communication' seen from a restorative lens, turned out to be deeper that we had imagined. Inquiring into conflicts and power relations, led us inevitably towards finding patterns of exclusion, of doubtful decision-making, of wrongs and rights. In these cases, positions of objectivity, neutrality or impartiality became difficult to maintain. The researchers as action researchers have to accept the impossibility of being equally credible to different groups, which the restorative 'philosophy' calls for. This led us to the realization that sometimes open verbalization of hidden conflicts or giving voice to repressed or silenced narratives of conflicts might be even more important than the outcome of achieving consensus between different parties. But even this basic feature of restorative justice, which is related to the fact that all parties have to speak and express themselves, turned out to be a radically subversive act. This taught us that we need to appreciate every instance where restorative actions make visible and sayable that which a particular configuration of power renders less available and less legitimate. 
Another important challenge related to the notion of participation. I discussed two core assumptions of the use of participation in restorative philosophy, one based on participation as ownership, and the other on participation as emancipation. The main insight for action researchers is the need to consider the levels of participation needed or desired in their projects right from the stage of the project design. Our research agenda was set from the research institutes, universities, and funding institutions, and only $a$ posteriori encouraged participation of the community in the action research. Although we have involved the community in all the research processes (ex. feedback groups, local research committees), the precarity of our research remained high given that the project was not designed from the beginning with the community on a problem that the community thinks is a problem. Nevertheless, the other question which I raised, and which remains legitimate is: Does a unified 'community' even exist? Would it be possible and realistic to deliberate and decide together with this community that the exclusion of the Roma from civic life and the harm it causes are important topics worth researching and eventually changing?

Finally, our assumption that participation in restorative approaches will reduce social exclusion because agreement and consensus could be reached, was also deeply challenged by our research. Power relations were never suspended and open communication required power sharing which not all parties were ready or willing to do. Participation can reinforce existing power relations, or it can be disruptive, create dissensus and challenge them. Our research showed to us that conflict can be one of the most important ways and means for locating and communicating contradictions, inequities and injustices that affect some people in their social formations. At the same time, it also highlighted the need to move in such contexts beyond the element of reparation towards more transformative objectives and strategies, in line with action research epistemologies. The necessity of aligning restorative interventions with a social justice agenda is paramount because when deep social inequalities combined with ethnic or other types of diversity undermine trust, thus making both communication and cooperation very precarious. The attempt must be on the one hand to minimize all possibilities for domination and exclusion through such practices and processes, and on the other hand to maximize opportunities for their contestation.

Aertsen, Ivo. 2018. "Action research in intercultural settings and restorative justice: setting the scene." In Action Research in Criminal Justice: Restorative justice approaches in intercultural settings, edited by Inge Vanfraechem and Ivo Aertsen, 10-28. London and New York: Routledge.

Aertsen, Ivo, and Tony Peters. 1995. Actie-onderzoek, een hefboom voor beleidsontwikkeling? Panopticon: 220-238.

Sherwood, Juanita, and Sacha Kendall. 2013. Reframing spaces by building relationships: Community collaborative participatory action research with Aboriginal mothers in prison. Contemporary Nurse 46 (1): 83-94.

Walsh, Elizabeth, Katrina Forsyth, Jane Senior, Kate O'Hara, and Jenny Shaw. 2014. Undertaking action research in prison: Developing the Older prisoner Health and Social Care Assessment and Plan. Action Research 12 (2): 136-150. 
Heather Noga, Alison Foreman, Elizabeth Walsh, Jenny Shaw, and Jane Senior. 2016. Multi-agency action learning: Challenging institutional barriers in policing and mental health services. Action Research 14: 132-150.

Wastell, David, Peter Kawalek, Peter Langmead-Jones, and Rob Ormerod. 2004. Information systems and partnership in multi-agency networks: an action research project in crime reduction. Information and Organization 14: 189-2010.

Saija, Laura, and Filippo Gravagno. 2009. Can participatory action research deal with the Mafia? A lesson from the field. Planning Theory \& Practice 10 (4): 499-518.

Vanfraechem, Inge, and Lode Walgrave. 2001. Een wetenschappelijk begeleid experiment met herstelgericht groepsoveleg. Panopticon: 479-493.

Bakhtin, Mikhail. 1981. The dialogic imagination: Four essays. London: University of Texas Press.

Berkovits, Balázs and Eszter Balogh. 2013. "Theoretical report on the main concepts in the communities: securitisation and minorities." Project Deliverable (D5.1) FP7 Project ALTERNATIVE. Leuven. www.alternativeproject.eu

Benedek, Gabriella, Gabor Hera, Koppány Kelemen, Eva Győrfi, Lazslo Balla, and Dora Szegő. 2015. "Implementation report on the application of RJ in the community: grasping action and research." Project Deliverable (D5.3) FP7 Project ALTERNATIVE. Leuven. www.alternativeproject.eu

Blase, Joseph, ed. 1991. The politics of life in schools: Power, conflict, and cooperation. Newbury Park, CA: Sage.

Brown, Wendy. 2005. Edgework: Critical essays on knowledge and politics. Princeton: Princeton University Press.

Brydon-Miller, Mary. 2001. "A glimpse of a lighthouse: Participatory action research, postcolonial theory, and work with refugee communities." Committee on refugees and immigration selected papers IX: 254-276.

Cherry, Frances, and Catherine Borshuk. 1998. "Social action research and the commission on community interrelations." Journal of Social Issues 54: 119142.

Christie, Nils. 1977. "Conflicts as property." British Journal of Criminology 17, $1: 1-15$.

Crabtree, Jeffrey, Jarrod M. Wall and David Ohm. 2016. Critical Reflections on Participatory Action Research in a Prison Setting: Toward Occupational Justice. Occupation, Participation, and Health 36 (4): 244-252.

Crawford, Adam, and Simon Hutchinson. 2016. "Mapping the Contours of "Everyday Security": Time, Space and Emotion." British Journal of Criminology 56: 1184-1202.

Cornwall, Andrea. 1996. "Towards participatory practice: Participatory rural appraisal (PRA) and the participatory process." In Participatory research in health: issues and experience, edited by Korrie de Koning and Marion Martin, 94-107. London: Zed Books.

Esposito, Roberto. 2012. Terms of the political. Community, immunity, biopolitics. Fordham: Fordham University Press.

Fellegi, Borbála, Gábor Héra and Gabriella Benedek. 2017. "To Talk or Not to Talk? The Limits and Potential of Restorative Justice in Addressing Social 
Inequalities." In Critical Restorative Justice, edited by Ivo Aertsen and Brunilda Pali, 193-210. Oxford, Portland: Hart Publishing.

Fine, Michelle, and Maria Elena Torre. 2004. "Re-membering exclusions: Participatory action research in public institutions." Qualitative Research in Psychology 1: 15-37.

Fine, Michelle, and Maria Elena Torre. 2006. "Participatory action research in prison." Action Research 4, 3: 253-269.

Héra, Gábor, Eva Györfi, Dora Szegő, Laszlo Balla, Koppány Kelemen, and Gabriella Benedek. 2014. "Community problem analysis: Building The Bridges of Trust With and Within The Communities." Project Deliverable (D5.2) FP7 Project ALTERNATIVE. Leuven. www.alternativeproject.eu

Héra, Gábor. 2015. Comprehensive final report on RJ in intercultural communities. Project Deliverable (D5.5) FP7 Project ALTERNATIVE. Leuven. www.alternativeproject.eu

Héra, Gábor. 2017. "Counteracting social exclusion through restorative approaches." In Restoring Justice and Security in Intercultural Europe, edited by Brunilda Pali and Ivo Aertsen, 93-109. New York: Routledge.

Herr, Kathryn, and Gerry L. Anderson. 2005. The action research dissertation: A guide for students and faculty. Thousand Oaks, CA: Sage.

Hodiaumont, Fabienne, Hannelore Malempré, Ivo Aertsen, Philip Daeninck, Tinneke Van Camp, and Tina Van Win. 2005. Vade-mecum justice reparatrice en prison. Gent: Academia Press.

Kidd, Sean A., and Michael Kral J. 2005. "Practicing participatory action research." Journal of Counseling Psychology 52, 2: 187-195.

Lykes, M. Brinton. 2001. "Activist participatory research and the arts with rural Maya women: Interculturality and situated meaning making. In From subjects to subjectivities: A handbook of interpretive and participatory methods, edited by Deborah L. Tolman and Mary Brydon-Miller, 83-199. New York: New York University Press.

Maguire, Patricia. 1987. Doing participatory research: A feminist approach. Amherst, MA: University of Massachusetts.

McTaggart, Robin, ed. 1997. Participatory action research. International contexts and consequences. Albany: State University of New York Press.

McTaggart, Robin. 2001. "Guiding principles of participatory action research." In Research in higher education: Expanding perspectives, edited by Clinton F. Conrad, Jennifer Grant Haworth, and Lisa R. Lattuca, 263-274. Boston: Pearson Custom Publishing.

Morley, Louise. 2016. "Institutional micropolitics." In The Wiley-Blackwell Encyclopedia of Gender and Sexuality Studies, edited by Nancy Naples. Wiley-Blackwell, London.

Miessen, Markus. 2010. "Democracy Revisited -In Conversation with Chantal Mouffe." In The Nightmare of Participation: Crossbench Praxis as a Mode of Criticality, 105-160. New York and Berlin: Sternberg Press. http:// www.sternberg-press.com/index.php?pageId=1270

Nowicka, Magdalena, and Steven Vertovec. 2013. "Introduction. Comparing convivialities: Dreams and realities of living-with difference." European Journal of Cultural Studies 17, 4: 341-356. 
Pavlich, George. 1996. Justice fragmented: Mediating community disputes under postmodern conditions. London: Routledge.

Pavlich, George. 2002. "Deconstructing restoration: The promise of restorative justice." In Restorative Justice: Theoretical Foundations, edited by Elmar Weitekamp and Hans-Jürgen Kerner, 90-109. Cullompton: Willan Publishing.

Reason, Peter, and Hilary Bradbury. 2001. "Inquiry and participation in search of a world worthy of human aspiration." In Handbook of action research: Participative inquiry and practice, edited by Peter Reason and Hilary Bradbury, 1-14. Sage Publications: London.

Reid, Pamela Trotman, and Vianna, Eduardo. 2001. "Negotiating partnerships in research on poverty with community-based agencies." Journal of Social Issues 57: 337-354.

Roche, Declan. 2002. "Restorative justice and the regulatory state in South African Townships." British Journal of Criminology 42: 514-533.

Shearing, Clifford D. 2001. "Transforming security: A South African experiment." In Restorative justice and civil society, edited by Heather Strang and John Braithwaite, 14-34. Cambridge: Cambridge University Press.

Schön, Donald A. 1983. The reflexive practitioner: How professionals think in action. New York: Basic Books.

Simmel, Georg. 1955. Conflict. New York: The Free Press.

Stolcke, Verena. 1995. Talking culture: New boundaries, new rhetorics of exclusion in Europe. Current Anthropology Special Issue: Ethnographic Authority and Cultural Explanation 36(1): 1-24.

Szegő, Dora, Gabriella Benedek, and Eva Győrfi. 2015. "Evaluation and follow up report." Project Deliverable (D5.4) FP7 Project ALTERNATIVE. Leuven. www.alternativeproject.eu

Szegò, Dora. 2018. "Participatory filming as part of action research in ALTERNATIVE: Experiences from four countries." In Action Research in Criminal Justice: Restorative justice approaches in intercultural settings, edited by Inge Vanfraechem and Ivo Aertsen, 43-59. London and New York: Routledge.

Szegò, Dora, Gabriella Benedek, and Eva Gyorfi. 2018. "Turning resistance to cooperation: Action research in Hungary." In Action Research in Criminal Justice: Restorative justice approaches in intercultural settings, edited by Inge Vanfraechem and Ivo Aertsen, 81-98. London and New York: Routledge.

Tandon, Rajesh. 1996. "The historical roots and contemporary tendencies in participatory research: Implications for health care." In Participatory research in health: Issues and experiences, edited by Korrie de Koning and Marion Martin, 19-26. London: Zed Books.

Vertovec, Steven. 2007. "Super-diversity and its implications." Ethnic and Racial Studies 30: 1024-1054.

Walgrave, Lode. 2008. Restorative justice, self-interest and responsible citizenship. Cullompton: Willan.

Walsham, Geoff. 2006. "Doing interpretive research." European Journal of Information Systems 15: 320-330. 
Wimmer, Andreas. 2007. How (not) to think about ethnicity in immigrant societies: A boundary making perspective. Working Paper No. 44, ESRC Centre on Migration, Policy and Society: University of Oxford.

\section{Acknowledgments}

The author wishes to thank the Foresee Research Group for their work and engagement in the FP7 Alternative project and their unwavering support and encouragement for my $\mathrm{PhD}$. 